\title{
Effect of Acebutolol on Plasma Catecholamine Concentrations in Anesthetized Dogs with Ouabain-Induced Arrhythmias and its Direct Actions in Vitro on the Adrenal Medulla
}

\author{
Toshiaki NAKAI*, Hideaki SAKIO**, TATsuji NAGAYAMA**, \\ HirotaKe ODE**, Ritsuji YAMADA*, \\ CHIAKI OKUDA** AND KenICHI IWATSUKI** \\ *Department of Clinical Pathology and **Department of Anesthesiology, \\ Dokkyo University School of Medicine, Mibu Town, Tochigi Prefecture, 321-02
}

\begin{abstract}
Abstruct
We have performed studies on blood hormone dynamics following intravenous administration of acebutolol, a newly synthesized $\beta$-blocker, and its direct action on the adrenal medulla in vitro.

Intravenous injection of acebutolol into anesthetized dogs almost doubled the plasma adrenaline and noradrenaline concentrations within 5 to 15 minutes, while renin activity was reduced to approximately two-thirds of the pre-administration level.

When arrhythmia was induced in dogs with ouabain, the plasma adrenaline and noradrenaline levels increased to $220 \pm 109$ and $392 \pm 84 \mathrm{pg} / \mathrm{ml}$, respectively, from the basal levels of $44 \pm 24$ and $140 \pm 43 \mathrm{pg} / \mathrm{ml}$. The restoration of sinus rhythm following the administration of acebutolol was accompanied by a further increase in the plasma adrenaline and noradrenaline levels to $797 \pm 364$ and $1226 \pm 263 \mathrm{pg} / \mathrm{ml}$, respectively. A perifusion experiment indicated that acebutolol directly accelerated catecholamine release from the adrenal medulla in pigs.
\end{abstract}

Acebutolol is a new beta-blocker which was synthesized by May \& Baker Ltd. Research Laboratory. When beta-blockers are used in the treatment of cardiac arrhythmia, development of bronchospasm and other side effects must be carefully watched. Acebutolol is reported to possess a high cardioselective beta-adrenoceptor blocking action. It had about $1 / 100$ th of the potency of propranolol in constricting the bronchial smooth muscle (Basil et al., 1973), and it is expected to be safer to use than propranolol in the treatment of cardiac arrhythmia.

In recent years, several reports. (Fleming and Hyman, 1974; Biron et al., 1975; Lewis et al., 1974; Miyazaki et al., 1977)

Received June 24, 1983 have been made on the results of the treatment of arrhythmia with acebutolol, and the changes in cardiovascular dynamics, such as in blood pressure and heart rate, have been made clear. However, there have been no reports concerning blood catecholamine dynamics when acebutolol is administered. In addition to blocking alpha- and betaadrenoceptors, alpha- and beta-blockers have been reported to act directly on the adrenal medulla, resulting in an increase or a decrease in catecholamine release (Kirpekar and Cervoni, 1963 ; Serck-Hanssen, 1974).

The authors used a modified experimental periperfusion system in order to examine the direct action of acebutolol on the adrenal medulla (Nakai and Yamada, 1977). This paper describes the results of the effect 
of acebutolol on plasma catecholamine concentrations in anesthetized dogs with ouabain-induced arrhythmia and its direct actions in vitro on the adrenal medulla.

\section{Methods}

1. The effect of acebutolol on plasma catecholamine concentrations and renin activity in anesthetized dogs

Six dogs $(10-15 \mathrm{~kg})$ of either sex were anesthetized with $20 \mathrm{mg} / \mathrm{kg}$ pentobarbital. The animals were artificially ventilated through a cuffed endotracheal tube with a tidal volume of $10 \mathrm{ml} / \mathrm{kg}$ at a frequency of $20 / \mathrm{min}$. The descending aorta was cannulated for blood sampling. Another cannula was inserted into the femoral vein for drug administration. In these experiments, blood pressure was recorded by means of arterial pressure transducers (MPU-0.5-290). All variables were recorded with a 4-channel polygraph (Sanei Instrument Co., Model 120).

A period of thirty minutes was allowed for stabilization of blood pressure. Then $0.4 \mathrm{mg} / \mathrm{kg}$ of acebutolol was administered intravenously. One $\mathrm{ml}$ arterial blood samples were withdrawn immediately before and after 1, 3, 5, 15, 30 minutes after the injection. Plasma catecholamines were determined by a radioenzymatic assay (Peuler and Johnson, 1977; Nakai and Yamada, 1980). Plasma renin activity (PRA) was measured radioimmunologically. Paired $t$-test was used for statistical analysis.

2. Comparison of the anti-arrhythmic effect of acebutolol and propranolol in anesthetized dogs

Twelve dogs $(10-15 \mathrm{~kg})$ of either sex were divided in the following two treatment groups: (1) acebutolol $(n=6)$; (2) propranolol $(n=6)$. The dogs were anesthetized with $20 \mathrm{mg} / \mathrm{kg}$ pentobarbital. Ouabain was administered intravenously in divided doses commencing with an initial dose of $40 \mu \mathrm{g} / \mathrm{kg}$. Twenty minutes later, $20 \mu \mathrm{g} / \mathrm{kg}$ was injected, followed by additional $10 \mu \mathrm{g} / \mathrm{kg}$ doses at 10 minute-intervals until persistent arrhythmia was obtained. When the arrhythmia had been stable for $10 \mathrm{~min}$, the test compounds were injected at intervals to restore the sinus rhythm. The test drugs were acebutolol and propranolol.

Acebutolol was started with a does of $2 \mathrm{mg} / \mathrm{kg}$, followed by another $2 \mathrm{mg} / \mathrm{kg}$ ten minutes later. Thereafter, $1 \mathrm{mg} / \mathrm{kg}$ was given at five-minute intervals. Propranolol was administered in the same way as the half doses of acebutolol. When the sinus rhythm was restored, the infusion of the test compounds was stopped. If the sinus rhythm was not restored before untoward symptoms were pro- duced (marked bradycardia or cardiac arrest), those animals were excluded from the calculation of the mean reverting dose. Blood samples for measurement of plasma catecholamine concentration were collected by way of an indwelling aortic catheter at 10 minute-intervals.

\section{The effect of acebutolol on the perifused adrenal medulla \\ Our modified perfusion technique (Nakai and} Yamada, 1977) was used in order to examine the direct action of acebutolol on the adrenal medulla in vitro. The continuous flow in this system makes it possible to monitor the changes in the secretory activity of the adrenal medulla over a period of time.

The pig adrenal glands used as the experimental materials were obtained from a local slaughter house. The adrenal glands were removed from the animals immediately after slaughter and were transported to our laboratory in an ice bath. The adrenal medulla alone was separated from the cortices as quickly as possible and minced finely. $70-80 \mathrm{mg}$ of the minced adrenal medullary tissue was first placed in a small chamber (capacity: $0.25 \mathrm{ml}$ ) and perifused with Ringer's solution delivered at a constant rate $(0.25 \mathrm{ml} / \mathrm{min})$ by means of a microinfusion pump. The effluent medium (Ringer's solution) was equilibrated with a $95 \% \mathrm{O}_{2}$ and $5 \% \mathrm{CO}_{2}$ mixture. The chamber containing the adrenal medullary tissue was fixed in a thermostat and maintained at $37^{\circ} \mathrm{C}$ throughout. The effluent perifusate was collected at 10 -minute intervals in test tubes kept at $4^{\circ} \mathrm{C}$, containing $2.5 \mathrm{ml} 0.4 \mathrm{~N}$ perchloric acid. The catecholamine concentrations in the perifusate collected in the test tubes were determined by a modification of the fluorometric method (von Euler and Floding, 1955; Anton and Sayre, 1964). The minimum sensitivity of this method was $0.1 \mu \mathrm{g}$ of adrenaline and noradrenaline and both intra- and inter-assay variations were equally within $10 \%$. In order to examine how the release of catecholamine from the adrenal medulla into the perifusion solution changed with the lapse of time, perifusion was continued for 4 hours, and the solution was collected at 10 -minute intervals in test tubes containing 2.5 $\mathrm{ml}$ of $0.4 \mathrm{~N}$ perchloric acid. During the course of perifusion, the initial release of a large volume of catecholamine dropped in about one hour and half to the basal level, and remained at that level thereafter. Infusion of $10^{-3} \mathrm{M}$ acetylcholine was conducted for 10 minutes 2 hours after the start of perifusion to examine the acetylcholine-induced release of catecholamine from the medulla. Ten minutes after the infusion, the perifused tissue was put back into Ringer's solution and perifusion was continued. Using the same experimental technique, infusion of $10^{-3} \mathrm{M}$ or $10^{-4} \mathrm{M}$ acebutolol in place of acetylcholine was conducted. These experiments 
were repeated six times.

\section{Results}

1. The effect of acebutolol on plasma catecholamine concentrations and renin activity in anesthetized dogs

In six dogs, the injection of acebutolol was followed by a marked increase in arterial adrenaline and noradrenaline concentrations, as shown in Table 1. Statistical analyses were performed by the paired $t$-test.
As shown in Table 2, plasma renin activity fell significantly 1 minute after the injection and remained below the control value for 30 minutes after injection.

2. Comparison of the anti-arrhythmic effect of acebutolol and propranolol in anesthetized dogs

The intravenous administration of ouabain produced persistent arrhythmia. The arrhythmia was reverted by an appropriate intravenous dose of the test drugs. The intravenous infusion of acebutolol resulted

Table 1. Plasma catecholamine concentrations and maximum changes in blood pressure and heart rate following intravenous acebutolol $(0.4 \mathrm{mg} / \mathrm{kg})$ in anesthetized dogs. Asterisks represent statistically significant changes compared with preadministration values $(* \mathrm{p}<0.05$ and $* * \mathrm{p}<0.01$, respectively)

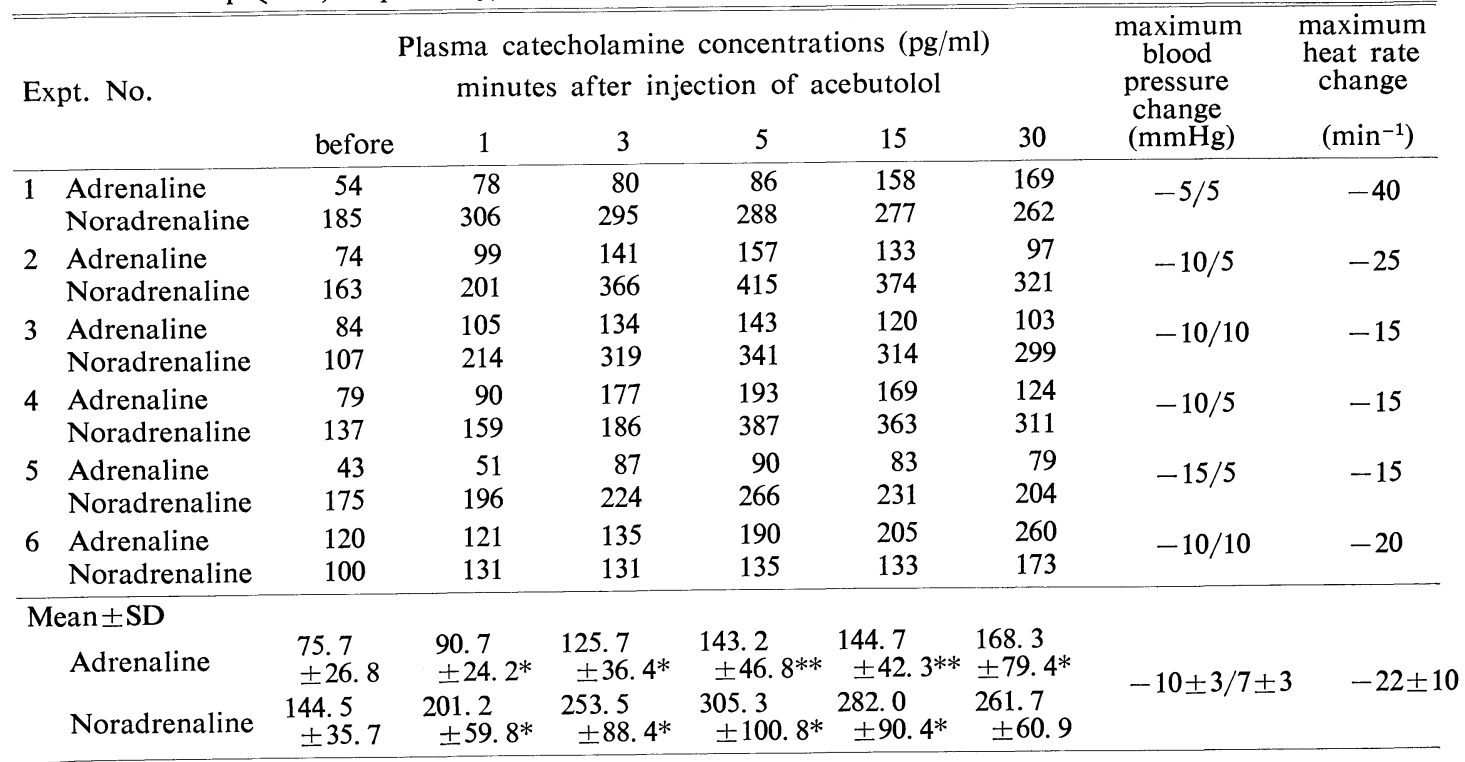

Table 2. Effect of acebutolol $(0.4 \mathrm{mg} / \mathrm{kg})$ on plasma renin activity $(\mathrm{ng} / \mathrm{ml} / \mathrm{hr}$ ) in anesthetized dogs. Asterisks represent statistically significant changes compared with preadministration values $(* \mathrm{p}<0.01$ and $* * \mathrm{p}<0.001$, respectively)

\begin{tabular}{lcccccc}
\hline \hline $\begin{array}{l}\text { Expt. } \\
\text { No. }\end{array}$ & \multicolumn{7}{c}{ Minutes after injection of acebutolol } \\
\hline 1 & before & 1 & 3 & 5 & 15 & 30 \\
2 & 9.6 & 6.8 & 6.8 & 6.8 & 7.0 & 7.6 \\
3 & 6.8 & 4.7 & 4.9 & 5.0 & 5.2 & 5.4 \\
4 & 8.6 & 6.0 & 5.5 & 5.8 & 6.0 & 6.9 \\
5 & 6.2 & 4.9 & 3.8 & 4.1 & 5.4 & 5.4 \\
6 & 8.2 & 5.2 & 4.7 & 4.4 & 5.0 & 6.0 \\
\hline Mean \pm SD & 7.4 & 4.6 & 4.1 & 4.2 & 4.7 & 5.0 \\
\hline
\end{tabular}


Table 3. Comparison of anti-arrhythmic effect of acebutolol and propranolol on ouabain-induced arrhythmia in anesthetized dogs

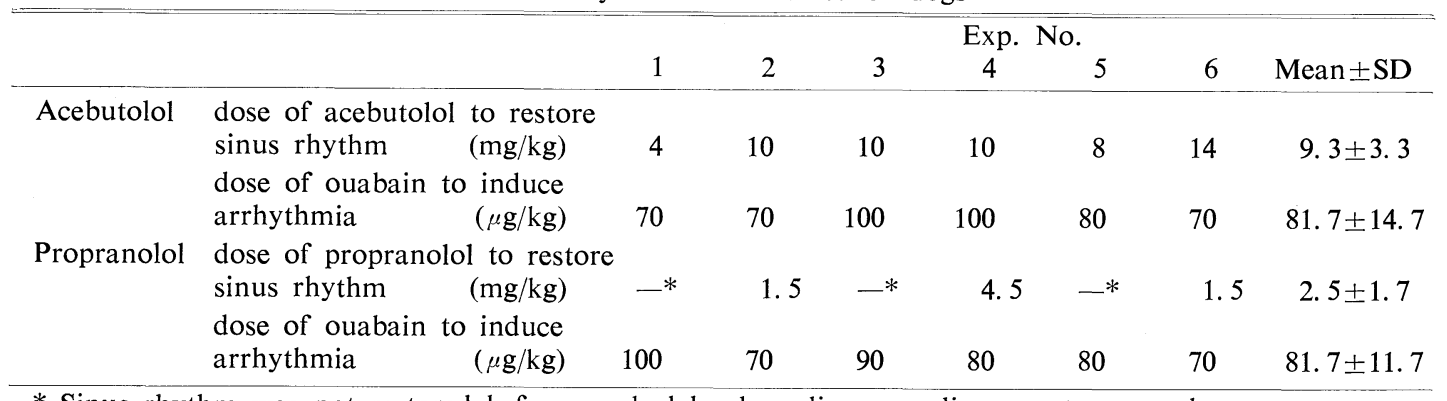

* Sinus rhythm was not restored before marked bradycardia or cardiac arrest occurred

Table 4. Plasma catecholamine concentrations in restoration of a sinus rhythm from the ouabain arrhythmia in anesthetized $\operatorname{dogs}(\mathrm{pg} / \mathrm{ml})$

\begin{tabular}{rlrcr}
\hline \hline Exp. No. & Basal & $\begin{array}{c}\text { Bage } \\
\text { stage }\end{array}$ & $\begin{array}{c}\text { Arrhythmia } \\
\text { stage }\end{array}$ & $\begin{array}{c}\text { Restored stage following } \\
\text { intravenous acebutolol }\end{array}$ \\
\hline 1 & Adrenaline & 48 & 298 & 1318 \\
& Noradrenaline & 164 & 433 & 1125 \\
2 & Adrenaline & 36 & 310 & 1064 \\
& Noradrenaline & 124 & 460 & 1438 \\
3 & Adrenaline & 28 & 50 & 506 \\
& Noradrenaline & 112 & 302 & 1078 \\
4 & Adrenaline & 90 & 320 & 942 \\
& Noradrenaline & 100 & 490 & 1464 \\
& Adrenaline & 34 & 216 & 425 \\
& Noradrenaline & 124 & 382 & 964 \\
& Adrenaline & 29 & 141 & 524 \\
& Noradrenaline & 216 & 286 & 1284 \\
\hline \multirow{2}{*}{ Mean \pm SD } & Adrenaline & $44 \pm 24$ & $223 \pm 109$ & $797 \pm 364$ \\
& Noradrenaline & $140 \pm 43$ & $392 \pm 84$ & $1226 \pm 203$ \\
\hline
\end{tabular}

in restoration of the sinus rhythm from the ouabain-induced arrhythmia in all six dogs tested at the mean dose of $9.3 \mathrm{mg} / \mathrm{kg}$. Propranolol restored sinus rhythm in three of the six animals. The mean intravenous dose was $2.5 \mathrm{mg} / \mathrm{kg}$ in these three dogs (Table $3)$. In the remaining three dogs, sinus rhythm was not restored before marked bradycardia or cardiac arrest occurred. The mean plasma adrenaline and noradrenaline concentrations just before the injection of ouabain were $44 \pm 24 \mathrm{pg} / \mathrm{ml}$ and $140 \pm 43 \mathrm{pg} /$ $\mathrm{ml}$, respectively. At the stage of arrhythmia, both adrenaline and noradrenaline concentrations increased considerably, as shown in Table 4. A more marked increase in plasma adrenaline and noradrenaline concentrations occurred when the sinus rhythm was restored, the mean values being $797 \mathrm{pg} / \mathrm{ml}$ and $1226 \mathrm{pg} / \mathrm{ml}$, respectively.

\section{The effect of acebutolol on the perifused adrenal medulla}

The catecholamine-release pattern from the pig adrenal medulla in response to acebutolol infusion is shown in Fig. 1. After 2 hours of preincubation, when the level of catecholamine release into the perfusate returned to the basal level and remained stabilized, $10^{-3} \mathrm{M}$ acebutolol was infused for 10 minutes. As a result, the output of adrenaline and noradrenaline abruptly rose from the basal 

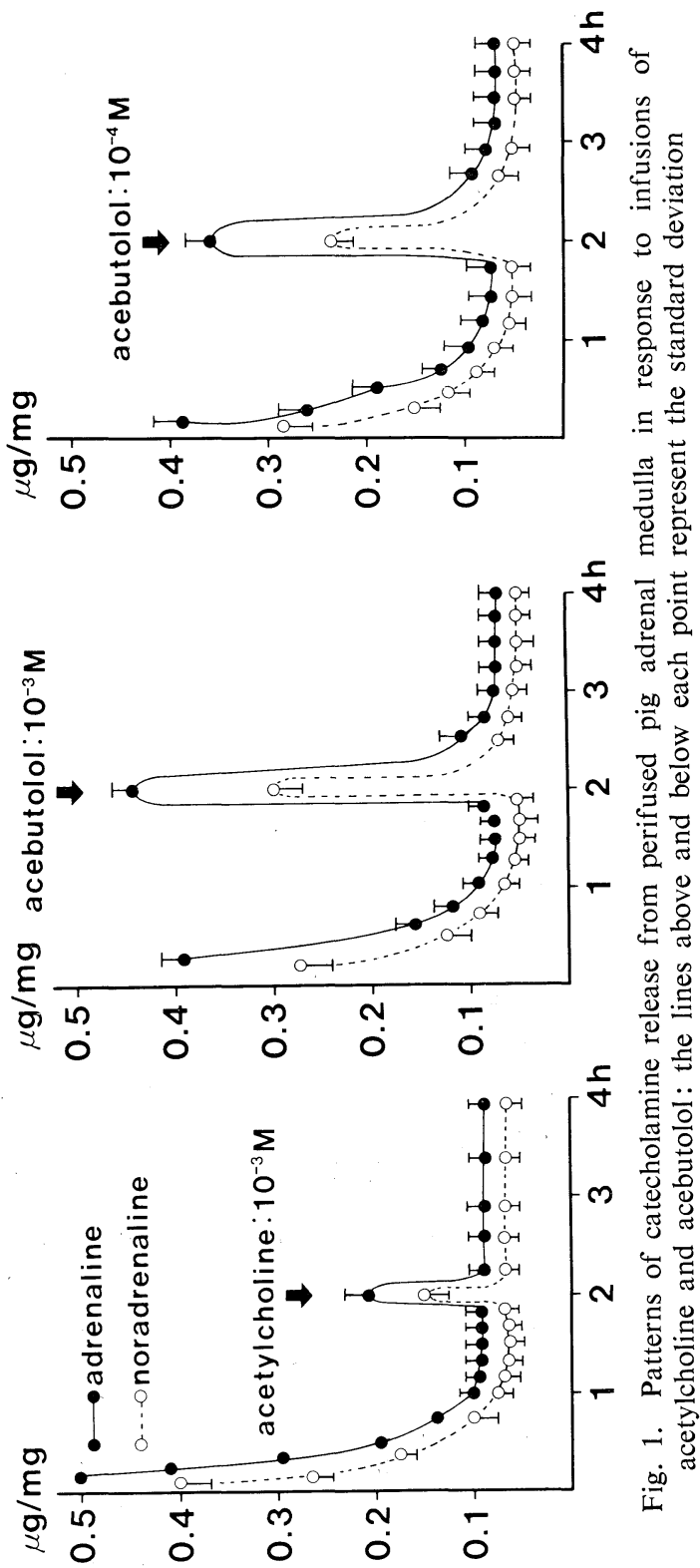

level of $0.07 \mu \mathrm{g} / \mathrm{mg}$ and $0.05 \mu \mathrm{g} / \mathrm{mg}$, to 0.45 $\mu \mathrm{g} / \mathrm{mg}$ and $0.30 \mu \mathrm{g} / \mathrm{mg}$, respectively, indicating the peak of catecholamine release. The stimulus of catecholamine release evoked by acebutolol was about twice as strong as that evoked by acetylcholine. This peak output promptly returned to the basal value after the withdrawal of acebutolol. When $10^{-4} \mathrm{M}$ acebutolol was infused following 2 hours of preincubation, an increase in catecholamine release into the perfusate was also observed, though the magnitude of the peak output was less than the corresponding peak with $10^{-3} \mathrm{M}$ acebutolol.

\section{Discussion}

Acebutolol is a cardioselective-beta- receptor blocking agent. There have already been several reports on the clinical studies of this preparation (Fleming and Hyman, 1974 ; Biron et al., 1975 ; Lewis et al., 1974 ; Miyazaki et al., 1977). However, no reports have been made on blood hormone dynamics following the administration of acebutolol.

Two sets of experiments were carried out. In the first, a single dose of acebutolol was administered intravenously to anesthetized dogs in order to examine the changes in plasma catecholamine concentration and plasma renin activity. It was found that, like other beta-blockers, the drug significantly reduced plasma renin activity. Recent evidence (Winer et al., 1969) indicates that the sympathetic nervous system also plays an important role in the control of renin release, and acebutolol, a beta-blocking agent, is considered to inhibit renin release.

An increase in plasma catecholamine level after acebutolol administration may be a secondary effect via the carotid and aortic baroreceptor reflex. Alternatively, it may be due to a direct action of acebutolol on the adrenal medulla, thereby stimulating catecholamine release. In fact, the direct effect of $\alpha$ - and $\beta$-blockers other than acebutolol on the adrenal medulla has been suggested (Kirpekar and Cervoni, 1963 ; Serck-Hanssen, 1974). Our present perifusion experiment has definitely proved that acebutolol directly affects the adrenal medulla and stimulates catecholamine release.

In the second set of experiments, plasma catecholamine levels before and after the 
administration of acebutolol as an antiarrhythmic agent were determined in anesthetized dogs. The arrhythmias were induced with ouabain, which was reproducible. Since it is reported that the effective dose of lignocain required to revert some types of arrhythmia in dogs was comparable to that in man (Basil et al., 1974; Jewitt et al., 1968), the effect of acebutolol in dogs may also be directly comparable to that in man. The employment of dogs with ouabininduced arrhythmia has the additional advantage in that it provides a single experimental model. Since arrhythmia in man is of various etiology, the mechanisms of the therapeutic effects of acebutolol on arrhythmia in man may not be simple, making the interpretation of experimental data difficult.

For these reasons, the present experiment was conducted by using anesthetized dogs in which arrhythmia was induced with ouabain. The results showed that the plasma catecholamine concentrations rose to double or three times those of the baseline level when arrhythmia was induced. After arrythmia was treated with acebutolol and the sinus rhythm was restored, the plasma catecholamine concentrations rose further to four to ten times those of the preadministration level. In spite of this marked increase in the plasma catecholamine concentrations, the action of catecholamine on the heart was found to be blocked by acebutolol.

In the present experiment on arrhythmia, propranolol was used as the control drug in order to compare its antiarrhythmic effect with that of acebutolol, and the results revealed that acebutolol could restore sinus rhythm in all animals tested, whereas propranolol failed to restore it in some animals, indicating that acebutolol was more effective than propranolol in reverting arrhythmia.

\section{References}

Anton, A. H. and D. F. Sayre (1964). The distribution of dopamine and dopa in various animals and a method for their determination in diverse biological material. J. Pharmacol. Exp. Therp. 145, 326-336.

Basil, B., R. Jordan, A. H. Loveless and D. R. Maxwell (1973). $\beta$-adrenoceptor blocking properties and cardioselectivity of M \& B 17, 803 A. Br. J. Pharmac. 48, 198-211.

Basil, B., R. Jordan, A. H. Loveless and D. R. Maxwell (1974). A comparison of the experimental anti-arrhythmic properties of acebutolol (M \& B 17803 A), propranolol and practolol. $B r$. J. Pharmac. 50, 323-333.

Biron, P., A. Proulx, L. Lapointe, R. Nadeau and G. Tremblay (1975). Properties of acebutolol in twenty patients with cardiac arrhythmias. Eur. $J$. Clin. Pharmacol. 8, 11-14.

Euler, U. S. von and J. Floding (1955). A fluorimetric micromethod for differential estimation of adrenaline and noradrenaline. Acta Physiol. Scand. 33 supple. 118, 45-56.

Fleming, T. S. and N. Hyman (1974). Treatment of cardiac arrhythmias: Use of acebutolol (Sectrol) in thirty patients. Clin. Trial. J. 3, 99-104.

Jewitt, D. E., Y. Kishon and M. Thomas (1968). Lignocaine in the management of arrhythmias after acute myocardial infarction. Lancet, i, 266270

Kirpekar, S. M. and P. Cervoni (1963). Effect of cocain, phenoxybenzamine and phentolamine on the catecholamine output from spleen and adrenal medulla. J. Pharmacol. Exp. Ther. 142, 59-70.

Lewis, B.S., A. S. Mitha and M. S. Gotsman (1974). Acebutolol in cardiac arrhythmias. S. A. Med. J. 48, 821-824.

Miyazaki, M., R. Muranishi and S. Yokono (1977). Clinical study on a new beta-adrenergic receptor blocker acebutolol in anesthesia. J. Kyoto Pref. Univ. Med. 86, 537-551.

Nakai, T. and R. Yamada (1977). An improved technique of perifusion system and its application for investigation of catecholamine release from perifused adrenal medulla. Jiritsushinkei 14, 121126 (abstruct, in English)

Nakai, T. and R. Yamada (1980). Studies on new radioenzymatic assay kit for catecholamine and plasma levels of catecholamines. Rinshobyori 28, 915-920.

Peuler, J. D. and G. A. Johnson (1977). Simultaneous single isotope radioenzymatic assay of plasma norepinephrine, epinephrine and dopamine. Life Science 21, 625-636.

Serck-Hanssen, G. (1974). Effects of theophllin and propranolol on acetylcholine induced release of 
adrenal medullary catecholamine. Biochem. Pharmac. 23, 2225-2234.

Winer, N., D. S. Chokshi, M. S. Yoon and A. D.
Freedman (1969). Adrenergic receptor mediation of renin secretion. J. Clin. Endocrinol. Metab. 29, 1168-1175. 